$\mathrm{M}$ AVERICK SCIENTIST, Richard Seed, has forced the debate on human cloning to the fore. While researchers the world over are speculating on his technical ability to achieve the first live birth of a cloned child, 20 European governments have rushed to sign an international treaty banning attempts in their own countries. Meanwhile, human cloning is not illegal in the US. Although Congress has blocked the use of Federal money for this type of research-under a one year Appropriations bill that is due to expire this September-they chose not to act on the advice of the National Bioethics Advisory Committee last year, which urged a five year moratorium on efforts to produce a child through cloning. For better or worse, Seed's antics mean that such legislation is widely anticipated now that Congress has reconvened. But it is perhaps unfair that cloning is receiving such concentrated attention in a country where many forms of reproductive research and technology are widely practiced and are barely reviewed, let alone regulated.

\section{US lacks reproductive technology regulation}

Unlike most of Europe, the United States does not require fertility clinics to be licensed by law. In fact, assisted reproduction is one of the least regulated medical specialties in the US. Although physicians and researchers in this field are reluctant to see stricter regulations imposed, not everyone agrees that this laissez-faire attitude serves the best interests of the consumer. "Most of the experimentation has been done on women as guinea pigs," says Lori Andrews, professor at the Chicago College of Law. "Debates about human cloning and using sperm from dead fathers have highlighted how far people are going in this field," says Andrews. "There are many Richard Seed's-they do not want to clone, but are trying out very experimental techniques."

Fertility research in the US is not federally funded, meaning that the industry has a lot more freedom. This allows purely commercial clinics to be set upsome of which have no hospital or research center affiliation. Attempts at introducing regulation are likely to meet with strong resistance; even the American Society for Reproductive Medicine (ASRM), which runs a voluntary accreditation program for clinics, does not see a need for tighter control. "The system is working pretty well as it is. There is an aversion to anything that comes between the relationship of patient and physician," says ASRM's Sean Tipton.

According to Andrews, "there is much need for consumer protection," not least because the nature of the procedures involved make it difficult for a couple to know when something goes wrong. "For instance, if all you know is that a procedure has a thirty percent success rate, how can you know whether failure is due to incompetence or to statistics," asks Andrews.

Moreover, there is tremendous variation among clinics with regard to the practices used. For example the length of time frozen embryos are kept in storage varies widely, as does the procedure by which they are disposed. Harrowing tales of frozen embryos being mailed back to couples at the end of their clinic storage time so that they can decide on the best method of destruction are not fictitious.

European legislation is considerably tighter. For example, many countries have restricted child conception using sperm from a dead father. And in the UK there is a limit on the number of embryos that can be implanted during in vitro fertilization (Nature Med. 3, 1309, 1997). Although the ASRM discourages
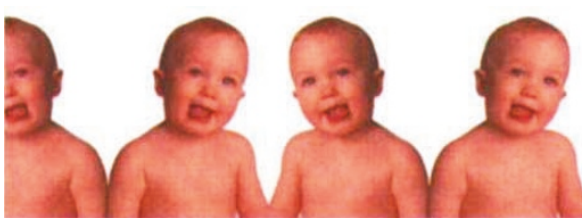

\section{US government issues first fertility clinic report}

Last month, the US Centers for Disease Control and Prevention (CDC) issued the first federal report on assisted reproductive technologies (ART) in fertility clinics across the nation. The document, entitled "Assisted Reproductive Technology (ART) Success Rates in the United States: 1995 National Summary and Fertility Clinic Reports," provides a summary of data on outcomes and pregnancy success rates of ART techniques performed at 281 reporting centers. It shows that ART resulted in the birth of 16,520 babies in the US in 1995.

The document is the first annual report to be issued under the terms of the Fertility Clinic Success Rate and Certification Act of 1992, sponsored by the then Senator of Oregon, Ron Wyden, which called for the CDC to publish pregnancy success rates of ART procedures. It was compiled in association with the Society for Assisted Reproductive Technology (SART), an organization of ART providers and an affiliate of the American Society for Reproductive Medicine (ASRM). The national consumer advocacy group, RESOLVE, also provided advice and is responsible for distributing the document. Although SART/ASRM have been the transfer of a large number of embryos (because multiple births increase the likelihood of elected multifetal reductions, as well the chance of premature birth), there is no law to enforce this recommendation. And according to the 1995 fertility clinics report issued by the Centers for Disease Control and Prevention, 37 percent of all live births resulting from assisted reproductive technology procedures were multiple births compared with only two percent in the general population.

LaURa BonetTa, NeW YorK

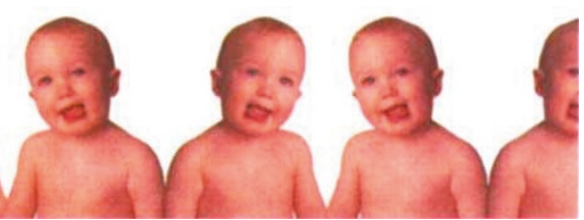

producing similar reports since 1989, this is the first time that the federal government has become involved. According to ASRM's Sean Tipton "it was felt that CDC participation would give more objectivity to the data."

Fertility figures, grouped according to procedure (either using non-donor egg and sperm or donor eggs, fresh embryos or cryopreserved embryos), show average success rates nationwide as well as for each reporting clinic. A list of all clinics refusing to report success rates will be published in the next report.

Because fertility clinics are not regulated by the government and "given that most insurance companies refuse to cover treatment for infertility, it is vital that consumers be as well informed as possible," says RESOLVE's executive director, Diane Aronson. In fact, the country's largest health insurer, Aetna US Healthcare, announced in January that it will drastically reduce coverage for ART as of April 1st, complaining that people have been joining the plan simply to take advantage of this expensive treatment.

Some physicians have already criticized the report. Jeffrey Steinberg of California-based Fertility Institutes is not satisfied with how data is presented. 